\title{
Subjects of conversion in colonial central India
}

This chapter raises key questions concerning religion, individualisation, and religious individualisation/institutionalisation. It does so by exploring the interplay of conversion, translation, and life-stories. Such interplay was embedded within processes of evangelical entanglements between EuroAmerican missionaries and central-Indian peoples in the nineteenth and twentieth centuries. Specifically, I focus on autobiographies and biographies of converts to Christianity in the Chhattisgarh region of central India, especially accounts written in the first half of the twentieth century. Here, the ordinary nature and the very details of these texts - mediated by procedures of vernacular translation - not only reveal the writings as key registers of evangelical entanglements. They further foreground critical queries that turn on religion and politics, individual and subject, individualisation and personhood, institutionalisation and akrasia. ${ }^{1}$

To anticipate the arguments that follow, the writings of convert subjects in colonial India put a question mark over the notion that individualisation and institutionalisation are opposed ideas. In such accounts, conversion and personhood, subject and author appear within emergent practices and performances of translation. Here, distinctive entailments of myth, legend, and narrative can break upon a missionary's description of a convert's life. At the same time, a son's story of his father's conversion uneasily reveals individuality and religious individualisation but only after drawing on classical figurations of the epic protagonist. Finally, a distinct autobiographical narrative of an Indian evangelical worker appears to be shored up by recalcitrance toward paternal authority and refusal of paternalist power - in a manner that the acute contrariness of the tale puts its particular twist to irony and akrasia (for instance, Henderson, this publication).

\footnotetext{
1 For some years now, I have been working on Christianity, conversion, and colonialism, conjoining central Indian ethnographic histories and North American cultural pasts. The present paper builds on such prior and ongoing work, based on a familiarity with wider archival, empirical, and theoretical questions. It is in this manner that I seize upon particular texts, broad questions, and their enactments in everyday arenas in order to address issues of the research group of which we are a part.
} 


\section{Overture}

In 1868, the Reverend Oscar Lohr of the German Evangelical Mission Society initiated evangelical work in Chhatisgarh. Over the next eight decades, six missionary organisations - including, the American Mennonites, the General Conference Mennonites, the Disciples of Christ, the American Evangelical Mission, and the Methodists - conducted their evangelical enterprise there. Aided by paternalist institutions such as Christian villages, hospitals, and orphanages, conversions to Christianity grew haltingly, primarily through ties of family and kinship and principally among lower-caste and adivasi (or indigenous) groups. On the one hand, the converts continued to understand missionary injunctions and to interpret evangelical truths through the grids of quotidian cultures. Drawing in the energies of their Western benefactors as witting accomplice and hapless victim, these peoples participated in the making of a colonial and a vernacular Christianity. On the other hand, the mission project itself unravelled through contradictory connections with colonial cultures. Furthermore, such processes in central India were intimately tied to those of congregations and Churches in Midwestern America. The missionaries had to leave India after its independence. In 1947, there were only around fifteen thousand Protestant Christians in a population of seven million in Chhattisgarh. At the same time, in independent India, as under imperial rule, the social and political significance of Indian Christians has exceeded their numerical unimportance (Dube 2004).

\section{Uncanny witness}

All of this now registered, I begin with the words of a catechist recounting his witness, his work of spreading the Word in a remote village in Chhattisgarh very early in the twentieth century. The catechist writes in a hesitant English while reporting on his labour to an American missionary, his employer. My purpose in rehearsing this example is to highlight the fact that, against the grain of stable figures of the individual and author, common sense forms of religion and history, and taken-for-granted apprehensions of (religious) individualisation and institutionalisation, it was the uncanny, the uncommon, and the unstable that often defined such subjects within evangelical entanglements. This will allow me to ask key questions and articulate critical categories turning on issues of the individual and institution, of religion and power, of religious individualisation/ institutionalisation, which presages my discussion of the writings of subjects of conversion in this essay. 
24 Monday [January 1908, the village of] Khaira. [Met] Kondu Gond. At the time of preaching, I saw a kid which was intended for sacrifice. I explained to him [Kondu] the object of sacrifice in ancient times and that he was right to offer a kid to appease his god for his sins but it was a symbol of Jesus Christ who would become incarnate and shed his blood for all mankind [...] 6 [people were] present.

(Entry for 24 January 1908 from the day-book of a catechist

[Anonymous], Manuscript, 83-5)

This brief passage bears an enormous burden. Early in his vocation of disseminating the Word in central India, the catechist encounters Kondu Gond, an adivasi who is about to sacrifice a kid, a baby goat. Yet the native evangelist does not disabuse Kondu of the 'superstitious' nature and the 'heathen' character of this action. Rather, the catechist is transported back to the density of descriptions of sacrifice in the Book, particularly the Old Testament, concerning, for example, the Mosaic sacrifice and the Lamb of God, the sacrifice of Abraham and the Lamb of Pascal. The catechist explains to Kondu the 'object of sacrifice in ancient times', linking this to the sacrifice of Christ.

Here it can be argued that the catechist is doing little more than elaborating a key tenet of Christianity, contrasting the variety and inefficacy of the Mosaic bloody sacrifices with the uniqueness and efficacy of the sacrifice of Christ for the forgiveness of sins. This idea poignantly appears, for instance, in the Epistle to the Hebrews:

Neither by the blood of goats and calves, but by his own blood he entered in once into the holy place, having obtained redemption for us. For if the blood of bulls and of goats, and the ashes of a heifer sprinkling the unclean, sanctifieth to the purifying of the flesh; How much more shall the blood of Christ, who through the eternal Spirit offered himself without spot to God, purge your conscience from dead works to serve the living God?

(Hebrews 9: 11-3. The Holy Bible, King James Version 1950, 226).

Yet this is not quite the catechist's intention, nor is it his representation. Rather, drawing a parallel between the sacrifices preceding Christ 'in ancient times' and Kondu's sacrifice of the kid in early twentieth century Chhattisgarh, he finds in both actions a prefiguring of the sacrifice of Christ. 'I explained to him [Kondu] the object of sacrifice in ancient times and that he was right to offer a kid to appease his god for his sins but it was a symbol of Jesus Christ [...]'. This is remarkable. As we know, Christianity recognises but one sacrifice, the sacrifice once offered by Christ in a bloody manner on the tree of the Cross. Yet, mixing together figures of the past and forms of the present, the Catechist is claiming that Kondu is correct in appeasing his god through the sacrifice of the kid, so long as there is clear recognition of what the goat and the sacrifice symbolise.

Of course, it is important to remember that the Redeemer Himself instituted the sacrifice of the Holy Mass so that the bloody sacrifice of Calvary could be 
continued and represented in an un-bloody manner. It was in this fashion that the merits of redemption won by the sacrifice of the Cross were to apply - once and forever - to individuals in sacrificial form, through constant sacrifice. At the same time, as a Protestant, the catechist did not argue from such grounds of Eucharistic sacrifice and its relation to the sacrifice on the Cross. Far from it: 'I explained to him the object of sacrifice in ancient times and that he was right to offer a kid to appease his god for his sins but it was a symbol of Jesus Christ who would become incarnate and shed his blood for all mankind'.

Through an ambivalence of verb tense and an uncertainty of subject (kid or Christ?), conjoining the past of the ancients and the present of evangelism, the catechist uniquely proposed that there was to be another incarnation and another sacrifice for the redemption of humankind. Of the kid or of the Christ, we cannot be sure. Of the stipulations of the King and the Cross (in the labour of sacrifice and the work of redemption), we do not know. Through excess of application to the Book, out of surplus of application of the Word, the catechist produced a supplementary narrative on the subjects of kid and Christ, sacrifice and redemption. The very literalism of his procedures - bringing to mind Walter Benjamin's advocacy of literalism in the task of translation - were definitional of practices of vernacular translation, about which more later.

\section{Critical categories}

My point now concerns staying with the questions raised by this passage and its implications for our deliberations. What does the encounter with, the entanglements of, this work of witness tell us about individualisation and institutionalisation? In what ways can the processes being described here be captured by the optics of religious individualisation/institutionalisation? What sort of a creature is the catechist - what kind of an individual, what manner of an agent, what variety of a subject, revealing which trajectories of individualisation and what processes of institutionalisation, religious or otherwise?

Questions of religious individualisation and institutionalisation - alongside those of 'de-individualisation' and the 'dividual' - have been discussed for long years now. Allow me to outline my orientations toward certain categories that might be critical for our deliberations. The exercise has much to do with approaching theory not as a prior overarching structure that frames an enquiry. Instead, theory and method are understood as ways of asking questions. It is in this way that theory-method are thought down to the ground, the demanding terms of everyday worlds, so that theory equally emerges as bound to narrative, each crisscrossing one another. 
In thinking through religious individualisation and institutionalisation, it might be useful to begin with religion, and then relatedly turn to power/politics. I approach religion as straddling the personal and the collective, the mundane and the sacred, the everyday and the institutional, epiphany and oracle, the ineffable and the obvious. Now, far from being antinomies, such elements (and copulas) often actually beget each other. This is because, for me, religion is immanent, turning on historical-cultural practices, meanings, and rituals of spatiotemporal subjects. Here are to be found rituals, meanings, and practices whose renderings and reconfigurations of worlds and divinities are closely tied to processes of authority and alterity, power and value, the appearance of the sublime and the making of the grotesque.

This is where politics, rendered as power, kicks in. For, I understand politics and power as extending further and deeper than merely routine institutionalised attributes of authority and governance centring on the state and its subjects. Rather, power and politics are articulated as equally embodying diffuse domains and the intimate configuration of authority and desire, including their seductions and subversions, turning on race and sexuality, gender and age, class and caste. All this has implications for how, as parts of such force-fields, we unravel the linkages of religion not only with power but with state, nation, and government, critically querying common sense presumptions of the secular and secularisation, all issues I have discussed elsewhere, including in several of the references cited in the bibliography to this essay. ${ }^{2}$ The question now is: where am I going with these musings? The response is simple. For me, issues of individualisation are, ultimately, better understood as involving formations of subjects, processes of subjectification, and performances of personhood, all of which turn upon meaning and power: power and meaning, authority and alterity that course through religions, politics, worlds, and the subject-agents who populate these procedures, including those of the productions, effects, and affects of institutionalisation.

Let me elaborate. Before projections of individualisation lie presumptions of the individual, before imaginings of institutionalisation lie images of the institutional. ${ }^{3}$ And so, it is our exact assumptions about the individual and the

2 State, nation, and government, their policy and program, now emerge as bearing twinned dimensions: entailing formidably embodied disciplinary techniques toward forming and transforming subjects-citizens, such protocols, and their reworking by citizens-subjects, register the shaping of authority by anxiety, uncertainty, and alterity, of the structuring of command by deferral, difference, and displacement.

3 I am speaking of epistemic precedence rather than a chronological precedence here, for the latter would simply return to what came first, the egg or the hen? Although if we believed in god-the-creator, the answer to the conundrum/riddle might depend on which divine, what faith, we practice. 
institutional that need to be examined and queried, critically and carefully. Is the individual being taken to exist across space and time, through history and across cultures? Is the individual, then, an innate staple of the world and therefore, thereby an a priori unit of analysis? In terms of ontological assumption and epistemic precedence, is the individual presumed to be pre-social, in the sense that it begets the social and the institutional, which are further apprehended as taken for granted entities-concepts? That is, is the individual Nietzsche's 'promise-making animal', who enters into binding relations of obligation and responsibility with other individuals to create society, institutions, institutional structures, institutionalised processes? Further, as an entitycategory that is already always present, is the individual simultaneously in front of the institutional?

Here, then, is the key query: In its exact essence, is the individual 'autonomous' from structure and the collective, institution and the institutional? (This is a query I draw not from the ether but actually from the result-statements and deliberations of the religious individualisation research group.) It is important to stay with, face up to, think through all this.

Now, I appreciate the interrogation within the religious individualisation project of the Eurocentric propensities that confine the 'individual' only to modern European and Euro-American worlds. At the same time, my question is different: does such an 'autonomous individual' exist anywhere? Or, is this figure the effect and an affect of particular processes of history, meaning, and power, a form that has subsequently been universalised, made to stand in as common currency across the world, over space, through time? This is to ask: is this projection of the autonomous individual shored up by pervasive presumptions of the bounded, intentional subject? Are we in the face of the autonomous individual as the sovereign subject who is seen as the privileged locus of action and reason? As the privileged locus of action and reason that is ever constrained by power and the collective, which this autonomous individual is seen as always militating against even as it begets the institutional, as a latter, external object? Is this the individual, autonomous, sovereign subject who articulates an adjudicatory, meaning-legislative rationality? Does not this rationality frame the objects it considers in the image of the commentator-analysts' singular, self-same reason rather than as subjects of other reasons? Are these images and mirrors not the means for the envisioning of the institutional and institutionalisation, which are already, always apart from the individual?

Let us retrace our steps. The key issue turns on meaningful human actors or agents in history and society. Now, mine is the not the silly suggestion that such meaningful human actors or agents in history and society simply do not exist. 
The question is different: Should such actors-agents be cast as 'individuals', especially autonomous ones or even otherwise? Or, are such agents better rendered as subjects? This is not terminological nit-picking. Far from it. Indeed, I am looking beyond the principally a priori singular individual to consider instead necessarily heterogeneous subjects. These innately heterogeneous subjects are ever formed and transformed within shifting processes and relationships of meaning and power, within diffuse and structured nodes, networks, institutions, which they create and are contained by, hardly ever under the circumstances of their choosing. (I have in mind relationships and processes, networks and nodes, institutions and structures - and of course subjects - that turn on divisions and solidarities. Here are to be found, for instance, solidarities and divisions of gender, sexuality, and hierarchy, which were outlined above. The processes equally entail wide-ranging articulations, over the past few centuries, of empire and nation, colony and modernity, as bound to the Renaissance and Romanticism, the Enlightenment and Anti-modernism, the Reformation and the Inquisition, to take a few examples.) The point is that in speaking of social actors as historical subjects my reference is precisely to their active participation in these broad relational processes of history and society. Such participation turns on two meanings of the term subject. That is, my reference is to social-spatial actors who have been both subject to (shaped by) these processes and relationships but also subjects of (themselves shaping) these relationships and processes (Dube 2017).

It follows that the place-play of power in the shaping of subjects is of enormous import here. For power and authority are no longer approached in terms of their exclusively repressive functions, whether as curbing autonomous individuals or as controlling recalcitrant collectivities. That is, I have in mind Foucault's famous undoing of the 'no-saying' propensity of power, which is to say power's 'thou shall not' stricture to its subjects. Rather, power is unravelled in terms of its productivity, fecundity, and promiscuousness but also its anxiety, ambivalence, and uncertainty (ibid.).

In terms of the dynamic between power and subject, at stake here are processes of subjectification: the ways in which formations of power and their seductions invite and entice human beings to make them subject to and subject of authority, including institutionalised disciplines of state and religion, offering and inciting action and imagination. Turning to the figure of the 'modern individual', 'autonomy' and 'individuality' have not been the end results of a developmental (or civilising) process. Rather, the claims upon and performances of 'individuality' and 'autonomy' are the (at once emergent and institutional) effects, affects, and consequences of the processes of subjectification. Indeed, since power is not simply an external force but an intimate commandment, here 
might be found variously the will to improve and progress, the desire to obey and respect, and the impulse to resist and challenge.

Now, if subjects and their formations are necessarily heterogeneous, ever enacted within wider processes of meaning and power, such subjects bear different personhoods - their senses of selves and others, cognates and affines, friends and enemies, images and colours, smells and sounds, and words and worlds. Understood in this fashion, the individual's is only one among distinct personhoods. Effectively, the individual is a particular sort of subject or agent or actor, who imagines and emotes, stages and rehearses, performs and practices, lives and loses her/his personhood, including autonomy and individuality, the institutional and the institutionalised, their fissures and fractures. As forms of personhood, such practices of becoming and being individuals can themselves vary enormously, as imagination and institutionalisation.

I acknowledge of course that the term individual can be used as implying simply meaningful human actors or agents in history and society. At the same time, the problem with any invocation of the 'individual' is that it readily and routinely takes us back to a singular abstraction, an a priori presence, that primary locus of agency. The haunting of knowledge and the world by this figure of the individual cannot be wished away. And so too what come to be overlooked are the different dimensions of the subject, their performance of personhood, including of the individual. ${ }^{4}$

Of course, no term is perfect. Actually, I am attracted to the very contrariness of subjects, the contrariness of the category-entity of the subject, including the mutual begetting of individualisation and institutionalisation under modernity. Indeed, it is in this spirit I distinguish between historically located 'subjects of modernity', bearing heterogeneous reasons/understandings, on the one hand, and routine representations of the 'modern subject', as insinuating a singular rationality, on the other (ibid; also Dube 2004). Rendered in practice, this distinction queries a meaning-legislative, adjudicatory reason; it grounds theory in the world; and it traces the active interchanges between subjects of modernity, modern subjects, and individual personhoods, that are all necessarily not-one. Here is heterogeneity that is not merely empirical but acutely critical. It is some of these concerns that I elaborate in the pages ahead.

4 Within the religious individualisation project, these issues have been imaginatively addressed by articulating the notion of the dividual and processes of de-individualisation. At the same time, I wonder if after all dividual and de-individualisation are not premised upon the grounds of individual and individualisation, which they seek to refute. Instead, I seize upon the idea-entity of the subject. 


\section{Questions of conversion}

I have shown elsewhere that dominant conceptions of conversion - as an 'individual' event or a 'collective' endeavour - are bedevilled by two overlapping difficulties (Dube 2010; 2003). First, they remain rooted in common sense European connotations of the category. Second, they turn conversion into a self-contained analytical apparatus, a self-generative descriptive domain. It is in this way that the event of conversion is widely understood as intimating a singular life and indicating an exclusive history for the convert, 'individually' and 'collectively'. At stake in thinking through such conceptions are wide-ranging questions that undergird issues of religious individualisation.

The autobiographical and biographical materials - as well as accounts of witness - explored in my paper narrate the words and worlds of subjects of conversion in colonial India. On the one hand, all too often, and particularly in social science literature, Christian conversion in non-western contexts appears as an essentially collective endeavour, opposing it to the image of the solitary Saul who sees the light in understandings of conversion in western arenas. Here modular understandings construe conversion as a search for meaning in front of the onslaught of modernisation/modernity in remote non-western theatres. A particular problem with such schemes lies in their tendency to bracket the distinct experiences of conversion, especially converts' notations of lives and histories and their performances of personhood. On the other hand, Pauline propositions and psychological prototypes regarding conversion tend to present it as an exclusively personal act, also intimating a solitary trajectory. Here the lone seeker transfers to a new, primary religious affiliation through a judicious choice among distinct and competing faiths, and then acts upon this choice through sincere personal belief and committed membership of community in Christ. Such understandings are based upon meta-historical and meta-cultural assumptions regarding action and understanding, the personal and the collective, conversion and Christianity. Unsurprisingly, these two opposed orientations can incline toward discounting what is salient and specific about lives and histories in the wake of conversion, the acute performances and practices of becoming and being Christian as attributes of distinct personhoods - the substance and spirit (or the stuff) of subjects of conversion.

We noted that most conversions to Christianity in colonial Chhattisgarh came about through networks of extended kinship, further entailing bonds of caste and sect, and the prospects of a better life under the paternalist economies of mission stations. Yet people also converted in other ways, variously negotiating kith and kin, caste and sect. Indeed, even those Christians whose conversion was effected through conduits of kinship were not simply figures of a singular, collective logic. 
In each case, conversion provided a resource for distinct plotting(s) of selves, different telling(s) of selfhood, discrete performance(s) of personhood, diverse enactments of individuality, disparate measures of subject-hood - being subjects, subjects of and subjects to. This is revealed by the writings discussed ahead.

These narratives were at once shaped by colonial verities and marked by vernacular attributes, both aspects of an evangelical modernity. Although apparently formulaic in nature, they engage and exceed the telos of dominant narratives of conversion to Christianity, further raising questions for proposals of religious individualisation. The accounts imbue such exclusive story lines with their own notations. Here conversion and personhood appear as processes, practices, and performances of translation, involving the entangled work yet the unequal labour of the convert and the missionary. They reveal that at the core of colonial histories and evangelical entanglements lie the complex making and unmaking of historical forms, social identities, ritual practices, mythic meanings, and narrative forms. If we are to find religious individualisation at all, it is within such matrices that we are obliged to do so, modalities of religious individualisation as beleaguered (not brave) protocols, turning on formations of subjects, processes of subjectification, and performances of personhood - all of this shored up by vernacular translation.

\section{Terms of translation}

Beginning with the issue of the impossibility of translation, which I have discussed elsewhere, the subject of translation is a vexed one (Dube 2008a). My point here is merely that, as George Steiner's $(1975,250)$ 'abundant, vulgar fact', translation is possible because it happens, and happens all the time in social worlds. Indeed, it is precisely the routine performance and the quotidian practice of translation that have been subject to critical considerations in recent times (especially Barnstone 1995). To begin with, in debates on cultural translation there has been keen recognition of what Talal Asad (1993, 171-99) has described as the 'inequality of languages'. Such inequality also implies inequity, the two together inscribing and re-inserting asymmetries of languages and idioms, knowledge and power in the name of a neutral science and in the guise of an authoritative translation. All of this has led to distinctive bids toward a critical-creative practice of translation in history and anthropology (for instance, Chakrabarty 2000, 7-18; Sakai 1997). It has also encouraged critical scholarship to emphasise that processes of translation were central to the elaboration of colonial cultures, instituting distinct forms of colonising power and eliciting diverse practices of colonised subjects (for example, Rafael 1988; Larson 1997; Peterson 1999; Fabian 1986; Mignolo 1995). Indeed, in the articulation 
of Christianity and colonialism, as Vicente Rafael $(1988,21)$ has argued, by 'setting languages in motion, translation tended to cast intentions adrift, now laying, now subverting the ideological grounds of colonial hegemony'. Here was dialogue and distinction that secured and subverted colonial power and missionary authority by construing these through familiar referents and unfamiliar premises.

At this point, it is important to clarify my use of the category vernacular translation. The notion at once builds upon and departs from Vicente Rafael's imaginative discussion of Spanish colonial and Christian translation among the Tagalog. Now, for Rafael (ibid., xi, 21, and passim), translation refers to certified practices involving clerical-colonial renderings of the Word and its attendant tools and texts into the vernacular. He describes the Tagalog 'response' to such processes as 'vernacularisation'. In contrast, my own focus concerns non-certified procedures of translation set in motion among Indian Christians in the wake of evangelisation and translation initiated by the Euro-American missionary. It is such procedures that I call vernacular translation. Put differently, vernacular translation does not simply indicate the linguistic rendering of texts and works from the English language into vernacular idioms. Rather, it equally refers to procedures of the transmutation of distinct categories and discrete concepts. These procedures lay between the interplay (and inequality) of languages, between the exchange (and inequity) of idioms, ever on the cusp of the English and the vernaculars, incessantly straddling and scrambling the boundaries and horizons of the original and the translation.

Understood in this fashion, the practices of vernacular translation that underlie the narratives in front inhabited the interstices brought into existence by the 'separation between the original message of Christianity [...] and its rhetorical formulation in the vernacular' (ibid., 20-1) by missionaries in colonial India. Indeed, as we shall soon see, the missionaries themselves could not escape the force and reach of vernacular translation. And so, procedures of vernacular translation often constrained the universalising assumptions of a colonial Christianity in British India. Yet, they did this not so much by turning away from its 'totalising impulses' as by imbuing these with an excess of meaning, a surplus of faith. In other words, vernacular translation illuminates Indian renderings of Christianity and empire but not simply as a 'response' to - which is to say, never ever split apart from - the Euro-American evangelist and colonial power. ${ }^{5}$ All this should become clear in the accounts ahead, which underscore that the terms of religious conversion are a critical resource to think through the concept of religious individualisation.

5 I elaborate these considerations of vernacular translation by reading the catechist's chronicles alongside the Bible and different missionary writings in English and Hindi in a book ahead (Dube forthcoming). 


\section{Divergent subjects}

I turn to two biographical accounts of the Reverend Ramnath Simon Bajpai, who was an evangelist of the German Evangelical Mission. One of these accounts was drafted by the missionary Theodore C. Seybold, who served in central India between 1913 and 1958; the other was written in 1958 by Ramnath Bajpai's son, David Bajpai. The two typescripts show particular overlaps but they also reveal critical differences. ${ }^{6}$

Specifically, the missionary Seybold's (Typescript undated) was a most singular rendering of the conversion of the Brahman Ramnath, which followed a given blueprint, a prior pattern. Yet, even in this account, to plot the life of a primordial upper-caste convert, a connection had to be made between an ancient prophecy, a pioneer missionary, and the lone seeker Ramnath Bajpai - uncanny tales at the core of evangelical encounters (Dube 1998). Where am I going with all this? On the one hand, in the testimony of Theodore Seybold, the conversion of Ramnath was exclusive in nature, based on the likeness of the solitary Saul who saw the light, intimating a novel trajectory of faith and life. What order of individuality and autonomy do we discover in the density of such descriptions that envision the life of an Indian convert in the image of the Apostles? If indeed we are to find religious individualisation and institutionalisation here, is this of a regular or an irregular kind? On the other hand, simultaneously in this account, the very terms of an immaculate conversion were acutely forged through the force of rumour and the strength of prophecy. This is to say that distinctive entailments of myth, legend, and narrative broke upon the missionary's description of Ramnath's life, placing a question mark on the exact terms of religious individualisation and institutionalisation. Thus, an exclusive rendering of conversion was yet enacted through wide-ranging formations of meanings, constitutively turning on processes of vernacular translation. Did this not acutely reveal both the convert Ramnath and the missionary Seybold as concrete and contrary subjects of evangelical entanglements? What does this tell us not just about the multiple mappings but the fraught registers of religious individualisation/institutionalisation?

This brings me to Ramnath's life-history that was written by his son, David Bajpai (Typescript 1945, 1-2). The account follows a different direction from the

\footnotetext{
6 Theodore Seybold served as a missionary in Chhattisgarh between 1913 and 1958. For nine years, he frequently met Ramnath Bajpai; Seybold lived for a long time in the home of the Missionary Jacob Gass; Ramnath was the head catechist working under Gass, and was often present in the missionary's home. Few biographical details are forthcoming about David Bajpai. I have earlier authored a wider and deeper discussion of the life-histories explored in this chapter (Dube 2008b, 259-90).
} 
missionary's narrative. It is based on a rather particular blueprint, that of the biography of an exemplary character, itself inflected by the lore of the learned Brahman. This story is based upon Ramnath's already distinguished ancestry, at once Brahmanical and martial, as well as his intellectual prowess as a student. This portrayal is rooted in the widespread lore of the learned Brahman conquering all with his liturgical abilities and scholarly propensities, so that he finds high office in a royal court. This tale is founded on Ramnath's own spiritual experience as envisioned in the mirror of Hindu darshan (vision/envisioning of divinity). Indeed, it is only after he is thus primed and presented that Ramnath Bajpai can sally forth to consummate his manifest, Christian destiny.

Ramnath is not just a mimic man or an acute double, simply envisioned in the evangelical mirror, in the likeness of the missionary or the image of the Apostles. In David Bajpai's account, Ramnath's sincere character and self-commitment to the Bible put him on a par with the missionaries, while distinguishing his persona from their personalities. It follows that distinct from the missionary Seybold's more straightforward account of Ramanth's change of faith, David Bajpai's narrative of his father's conversion traverses a jagged trajectory. In the missionary's tale, a single string binds Ramnath's conversion with his baptism - his formative change of spiritual orientation with his formal entry into the Christian church where each step is marked by a breach with the past.

The son's story exceeds the life of the convert as a reflection of the history of the mission. On the one hand, Ramnath's upright character and his selfcommitment to the Word - on par with the missionary, yet innately different seemingly surmount all obstacles in his path to conversion. They lead Ramnath inexorably toward his entry into the community of Christ through baptism. On the other hand, bonds of caste and kin constitute more than hurdles that are deftly overcome by the enquirer-into-convert. Rather, they also bear a distinct gravity, a discrete force. It is Ramnath's realisation of the rupture with these ties and the fear this engenders that lead him to seek refuge among Christians, unto his conversion through baptism - as a last step, a final resort. Indeed, we are at last, possibly in the face of an account that uncertainly betokens autonomy, individuality, and religious individualisation, which are yet grounded in the classical, figurations of the ancient, not unlike the entanglements of the concept of the modern, as Hans Ulrich Gumbrecht (1992) reminds us.

At the same time, David's was a lone text. Few autobiographical accounts embedded in the evangelical encounter could take for granted the distinctiveness of their own lives. Here the uncommon and the unremarkable had to be conjured and construed; the distinctive and the routine had to be reckoned with and sorted out. Such is the case with most of the writings of native evangelical workers, elicited by missionaries in the 1920s and 1930s, possibly for publication, as well as 
the life stories of Indian Christians, which I collected in the 1990s for the purpose of research. Mired in the common and the quotidian, in various ways these narratives dramatised the ordinary as the remarkable and pursued the uncommon in the everyday. In the case of all these narratives, it would be much too facile to present the lives they narrated as 'all-of-a-piece', whether seen through the optics of individualisation or sieved through filters of conversion. To do so will be to ignore the 'inner tensions - the fluctuations and hesitancies between opposing ideas or moods' that run through such accounts, as Arthur O. Lovejoy (cited in Kern 1983, 10) reminded us many, many decades ago. The attempt of these narratives was to revealingly dramatise the very commonness of the lives of their protagonists. Such dramatisations were themselves propelled and circumscribed by the constitutive tensions of the accounts. Here, an acute contrariness can run through several of these accounts - 'inner tensions' escape and exceed the exclusive life of the convert insinuated by dominant conceptions of conversion and put a distinct spin on notions of religious individualisation.

As an illustration of what I have been arguing, let me briefly turn to the 'Life Story of Johann Purti', a typescript of three and a half pages, which was first drafted by J. Purti (Typescript 1934) and then typed by a missionary in April 1934. At the beginning, through an emphasis upon geographical detail and historical chronology, Johann Purti establishes his ancestry and the fact that he was born a Christian. Here there is no rhetorical rhapsody or tortured tale of religious transformation. ${ }^{7}$ A simple sentence suffices: 'After Sepoy Mutiny in 1857 he [Purti's grandfather] became a Christian and was named Samuel Purti in baptism' (ibid.). Next, the account quickly covers Johann's initial lack of interest in attending school, his appreciation of learning upon moving to a boarding house, and his return home in the last year of high school after discovering that his father was borrowing money for his education. None of this is remarkable, hardly preparing us for the change of tone that now follows.

After leaving school my father asked me to join the Theological Seminary but I refused, telling him that one who wanted to be a padre should join because I looked down on the padres. Then my father asked me to learn the work of petition writer in the court but I said to him that one who would tell a lie and would rob the poor, should go to the court. Then my

7 Indeed, conversion does not appear as a dramatic or miraculous event in any of the life histories written or narrated by Christians in Central India that I consulted for this essay. This is true of various autobiographical accounts of women and men in Chhattisgarh today. It also holds for narratives written in the colonial period. If contrary tendencies characterise David Bajpai's story of his father's conversion and Johann Purti narrates the event of his grandfather's becoming Christian as an un-dramatic fact, even those accounts in which conversion was accorded centrality told the tale in rather low-key ways. 
father asked me to get a position in the railway or in the Forest Department. I answered him that one who wanted to be a vagabond should join these two lines. Then my father asked me what should I do. I told him I would be a farmer. Outwardly he assented but inwardly he wanted that I should change my mind. So he began giving me very hard works. I was working with servants as servants. I was working so hard that it changed my mind. I went to a relative who was a doctor with the intention to learn the work of a compounder but I was not satisfied and wanted to go to a great hospital for which I asked a recommendation from the Principal of my school (ibid., 1-2).

This unusual passage introduces us to the critical devices shaping Johann Purti's autobiographical account, which together constitute a curious amalgam. First, the narrative is entirely cast as that of a life seeking an occupation, an existence stalking a vocation. Second, recalcitrance toward paternal authority, refusal of paternalist power, runs through the text. Third, a perpetual note of dissatisfaction afflicts the protagonist of this story, which is also the basis of his recalcitrance. Fourth, the sources of this discontent often lie in the nature of the occupation ahead of Johann Purti and in the hardships such work entails, which teach him a lesson. Yet, the roots of this discontent equally constitute an existential condition. Fifth, abrupt changes of mind as much as God's guidance lead our protagonist in his choices of career. Sixth and finally, such tropic designs - especially, the salience of occupation, the place of recalcitrance, and the presence of dissatisfaction - pattern the entire narrative, driving it toward its resolution. Here the critical forms are the vocation of a padre and the work of a compounder. Yet like the narrative itself, the resolution too is unstable.

Let me explain. After miraculous encounters with passages from the Book of Timothy in the Bible, Johann accepts the vocation of a padre in 1927, declaring that he was 'now a compounder of the greatest physician Jesus' (ibid., 4). How might we read the end of Johann's story? It is not only that the transformation that follows Johann's encounter with passages of the Book loses some of its motive force because obedience to God's command had also characterised his earlier life. It is also that the resolution itself - Johann's becoming a compounder of the greatest physician Jesus - is not simply joyous. Instead, it is equally accompanied by an acute note of discontent. ${ }^{8}$ The point is that the acute contrariness that runs through this account also echoes the contrariness of the subject that was discussed earlier. It bids us to ask: In what ways does such contrariness of the

8 Elsewhere, I have discussed a critical conflict that consumed Purti's life and vocation (Dube 1995, 171-201). It is worth noting here that the precise terms of its dramatisation and the exact form of its contrariness distinguish Johann's tale from other life histories within the evangelical encounter. While the contrast with the writings of Theodore Seybold and David Bajpai should be abundantly clear, it equally extends to other accounts, written and oral (Dube 2008b). 
subject square up with the terms of religious individualisation? Or, is the contrariness of this subject better articulated in terms of historical irony and the embodied akrasia of evangelical entanglements?

\section{Coda}

And so we return to the catechist with whose account I began. Had the catechist read the Word in English, in the original? Had he read the Book in Hindi, in translation (itself carried out by missionaries)? Had he read the Bible in both, in original and in translation? ${ }^{9}$ The catechist had rendered God's Word in Hindi and reported on his labour in English, enacting procedures of reading, translation, and life that yielded difference rather than equivalence, subject rather than the individual. Might this have something to say to, some stuff to ask of, projections of religious individualisation/institutionalisation?

\section{References}

Anonymous. 1908. 'Entry for 24 January 1908 from the day-book of a catechist (not named)', Manuscript, 83-5, Eden Archives and Library, Webster Groves, Missouri. [Henceforth, EAL]. Asad, Talal. 1993. Genealogies of Religion: Disciplines and Reasons of Power in Christianity and Islam. Baltimore: The Johns Hopkins University Press.

Bajpai, David. 1945. 'My Father - Rev. Simon Ramnath Bajpai', Typescript, 84-9b Bio 52. EAL. Barnstone, Willis. 1993. The Poetics of Translation: History, Theory, Practice. New Haven: Yale University Press.

Chakrabaty, Dipesh. 2000. Provincializing Europe: Historical Thought and Postcolonial Difference. Princeton: Princeton University Press.

Dube, Saurabh. 1995. 'Paternalism and Freedom: The Evangelical Encounter in Colonial Chhattisgarh, Central India', Modern Asian Studies, 29. 171-201.

Dube, Saurabh. 1998. Untouchable Pasts: Religion, Identity, and Power among a Central Indian Community, 1780-1950. Albany: State University of New York Press.

Dube, Saurabh. 2003. Genealogías del presente: Conversión, colonialismo, cultura. Trans.

A. Bartra, G. Conde. Mexico City: El Colegio de México.

Dube, Saurabh. 2004. Stitches on Time: Colonial Textures and Postcolonial Tangles. Durham/ London: Duke University Press.

9 As I argue elsewhere, it is important to think through such ambiguities and tensions, which do not admit clear resolution, while discussing them in context-bound ways (Dube forthcoming). 
Dube, Saurabh. 2008a. 'Conversion to Translation: Colonial Writings of a Vernacular Christianity'. In Enchantments of Modernity: Empire, Nation, Globalization, ed. S. Dube, New Delhi/London: Routledge. 133-67.

Dube, Saurabh. 2008b. 'Witnessing Lives: Conversion and Life-history in Colonial Central India'. In Ancient to Modern: Religion, Power, and Community in India, eds. I. Banerjee-Dube and S. Dube, New Delhi: Oxford University Press. 259-90.

Dube, Saurabh. 2010. After Conversion: Cultural Histories of Modern India. New Delhi: Yoda Press. Dube, Saurabh. 2017. Subjects of Modernity: Time/Space, Disciplines, Margins. Manchester: Manchester University Press.

Dube, Saurabh. Forthcoming. In Other Tongues: Indian Writings of a Vernacular Christianity Delhi: Primus Books.

Fabian, Johannes. 1986. Language and Colonial Power: The Appropriation of Swahili in the Former Belgian Congo 1880-1938. Cambridge: Cambridge University Press.

Gumbrecht, Hans Ulrich. 1992. 'A History of the Concept “Modern”'. In Making Sense in Life and Literature, Hans Ulrich Gumbrecht, trans. Glen Burns, Minneapolis: University of Minnesota Press. 79-110.

Hebrews 9: 11-13. 1950. The Holy Bible. King James Version. New York: American Bible Society. 226.

Henderson, Ian H. This publication. '“[...] quod nolo, illud facio' (Romans 7:20): Institutionalizing the Unstable Self'.

Larson, Pier M. 1997. 'Capacities and Modes of Thinking: Intellectual Engagements and Subaltern Hegemony in the Early History of Malagasy Christianity', The American Historical Review, 112, 4. 969-1002.

Lovejoy, Arthur 0.1983. Cited in Stephen Kern, The Culture of Time and Space 1880-1918. Cambridge, Mass.: Harvard University Press.

Mignolo, Walter. 1995. The Darker Side of the Renaissance: Literacy, Territoriality, and Colonization. Ann Arbor: University of Michigan Press.

Paul, M. M. Undated. 'Autobiography of M. M. Paul, Head Catechist at Mahasamund', Typescript, 84-9b Bio 52. EAL.

Purti, Johann. 1934. 'Life Story of Johann Purti', Typescript, 84-9b Bio 52. EAL.

Rafael, Vicente. 1992. Contracting Colonialism: Translation and Christian Conversion in Tagalog Society Under Early Spanish Rule. Durham: Duke University Press.

Sakai, Naoki, 1997. Translation and Subjectivity. Minneapolis: University of Minnesota Press.

Seybold, Theodore. Undated. 'The Reverend Ramnath Simon Bajpai', Typescript, 84-9b Bio 52. EAL.

Steiner, George. 1975. After Babel: Aspects of Language and Translation. London: Oxford University Press. 
